\title{
Acquired Solitary Kidney
}

National Cancer Institute

\section{Source}

National Cancer Institute. Acquired Solitary Kidney. NCI Thesaurus. Code C128147.

A finding of one kidney after the loss of the second, whether due to injury, disease or surgery. 